\title{
Nurses' Knowledge on Prevention of Catheter- Associated Urinary Tract Infection in a Selected Hospital of Mangaluru
}

\author{
Anns M. Benny ${ }^{1}$ Anju S. Idiculla ${ }^{1} \quad$ Annmary Kunjumon ${ }^{1} \quad$ Anuja George ${ }^{1} \quad$ Anusha Roseline A. ${ }^{1}$
}

Sonia K.L. Sequera²

${ }^{1}$ Father Muller College of Nursing, Kankanady, Mangaluru, India

${ }^{2}$ Department of Community Health Nursing, Father Muller College of Nursing, Kankanady, Mangaluru, India

\begin{abstract}
Address for correspondence Sonia K.L. Sequera, MSc, PGDC, Department of Community Health Nursing, Father Muller College of Nursing, Father Muller Road, Kankanady, Mangaluru 575002, India
\end{abstract} (e-mail: soniakaren@fathermuller.in).

J Health Allied Sci ${ }^{\mathrm{Nu}}: 2020 ; 10: 128-131$

\begin{abstract}
Introduction Catheter-associated urinary tract infection (CAUTI) is one of the most common health care-acquired infections encountered in clinical practice. The most important predisposing factor for CAUTI is the insertion and prolonged use of indwelling urinary catheter, which has been performed by unsterile technique, and by not taking adequate measures to maintain cleanliness of the catheter. This study aimed to assess the knowledge on prevention of CAUTI among staff nurses in a selected hospital of Mangaluru.

Materials and Methods Staff nurses working in medical college hospital with National Accreditation Board of Hospitals and Healthcare Providers accreditation were included in this cross-sectional descriptive study. Structured knowledge questionnaire was used to assess nurses' knowledge on CAUTI. Frequency, percentage, mean, standard deviation, and Chi-square test were used for association.

Results Majority of nurses (80.85\%) had average knowledge on prevention of CAUTI, whereas $11.2 \%$ nurses had low knowledge and few (7.231\%) nurses had high knowledge regarding CAUTI. Association was found between knowledge and age (0.013),

Keywords

- knowledge

- prevention of CAUTI

- nurses educational qualification (0.018), and encounter with patients with CAUTI $(0.00)$ is $<0.05$, at 0.05 level of significance

Conclusion Pooled results showed that majority of the nurses had average knowledge on prevention of CAUTI.
\end{abstract}

\section{Introduction}

Urinary tract infection (UTI) is a common infection among health care setting. Urinary catheter insertion is considered as the most important predisposing factor for CAUTI and almost $25 \%$ of them undergo urinary catheterization during their stay in the hospital. ${ }^{1}$ The other risk factors include the unnecessary prolonged usage of indwelling urinary catheter, which has been performed by unsterile technique, and by not taking adequate measures to maintain cleanliness of the catheter. The daily risk varies between 3 and 7\% for an acquisition of bacteriuria when Catheter remains in place. ${ }^{2}$
The global burden of Hospital-acquired infection (HAI's) is underestimated in developing countries due to lack of surveillance systems. The Association for Professionals in Infection Control and Epidemiology (APIC-2014) in the United States also reported that CAUTI is accounting for $25.6 \%$ of all HAIs. This association also stated that CAUTI has been associated with increased morbidity, mortality, hospital cost, and length of stay. ${ }^{3}$ A study on incidence and risk factors of UTI on catheterized patients admitted at tertiary care hospital of Nizamabad, Telangana, India, showed that incidence was maximum in the age group of 51 to 70 years, especially in females (69.44\%) and was directly proportional to duration
License terms

(ㅇ)( $\Theta \circledast$ 
of catheterization. ${ }^{2}$ Thus, avoidance of unnecessary catheterizations and removal of catheters as soon as possible are the most effective preventive measures of CAUTI. ${ }^{2}$

When an episode of CAUTI becomes symptomatic, the resulting sequelae can range from mild (fever, urethritis, and cystitis) to severe (acute pyelonephritis, renal scarring, calculus formation, and bacteremia). If left untreated, these infections can lead to urosepsis and death. ${ }^{4}$ Prevention of CAUTI is one of the indicators among the National Accreditation Board of Hospitals and Healthcare Providers (NABH) or Quality Assured Institutions and one of the quality indicators to prevent hospital-acquired infection is reduction in CAUTI in hospital. ${ }^{4}$

Nurses are considered as the primary health care providers who are responsible for inserting and maintain of urinary catheters, as well as production of desired outcomes. Nurses are also accountable to acquire appropriate knowledge and practices of catheter care that will prevent UTIs. ${ }^{2}$

This study aimed to assess the knowledge on prevention of CAUTI among staff nurses working at a selected tertiary care hospital in Mangaluru. It is very important that health care professionals are skillful and competent enough with their knowledge and skills to prevent UTI among the hospitalized patient under indwelling catheter and also give adequate knowledge to patients regarding the prevention of CAUTI.

\section{Materials and Methods}

A descriptive survey design was used in this study to determine 235 staff nurses' knowledge on prevention of CAUTI at a selected medical college hospital with NABH accreditation in Mangalore with the total bed strength of 1,250, using purposive sampling technique. Sample size was calculated using Raosoft software with a population size of $600,5 \%$ of margin of error, $50 \%$ response distribution, and 95\% confidence interval (CI). Information was collected by administering a structured knowledge questionnaire which comprised of 17 questions. Content validity was collected by administering knowledge and questionnaire to seven experts from nursing- and medical-related fields.
The internal consistency of the tool was found to be reliable $(r=0.76)$. The final tool had baseline proforma, along with structured knowledge questionnaire on CAUTI in multiple-choice question (MCQ) format. The questions were based on application of theoretical knowledge in their practice setting. Questions were categorized into three domains. Domain 1 included exclusive theoretical questions related to meaning, anatomy, and physiology of UTI; domain 2 regarding etiology, risk factors, and signs and symptoms; and domain 3 consists of diagnosis, treatment, prevention, and complication. The second and third domain was based on the knowledge questions related to their practice. Scores $\geq 80 \%$ were considered to have good knowledge and score of $\leq 50$ was considered to have poor knowledge.

The ethical clearance was obtained from the ethical committee and permission from the hospital authority was taken to conduct the study. Informed consent was obtained and confidentiality of information was assured. Pilot study was done and no issues related to the study were identified. The main study was done and the average time taken to complete knowledge questionnaire was approximately 15 to 20 minutes. The data collection was terminated by thanking the patients for their participation and cooperation. The collected data were compiled for analysis.

\section{Results}

The data were analyzed using SPSS version 16 .

The knowledge of nurses on prevention of CAUTI showed that majority of nurses 190 (80.85\%) had average knowledge whereas, 28 (11.2\%) had low knowledge, and few 17 (7.23\%) nurses had high knowledge regarding CAUTI.

In this study the mean age of the staff nurses was $25.30 \pm 6.11$ years, and majority have completed BSc nursing $(65.1 \%)$ with the mean working experience of $6.49 \pm 2.37$ years.

More than half (52.3\%) have received information through continuing nursing education and majority of the staff nurses (81.7\%) have encountered the patients with CAUTI.

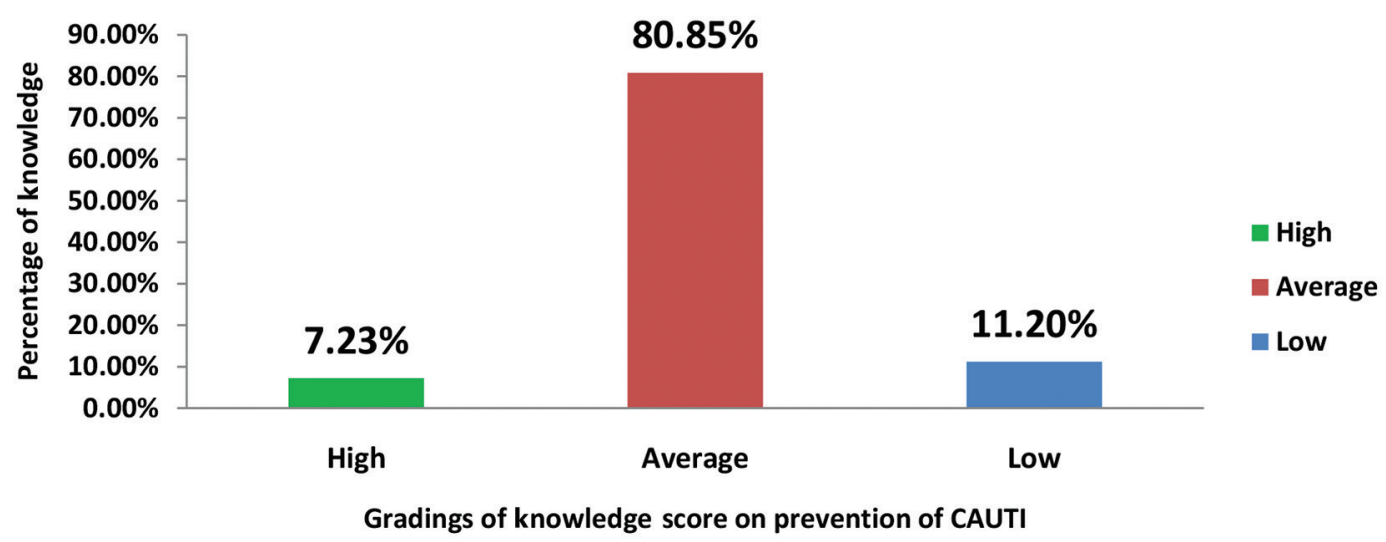

Fig. 1 Bar diagram showing distribution of nurses according to their knowledge level on catheter-associated urinary tract infection (CAUTI). 
-Fig. 1shows that majority of the nurses 190 (80.85\%) had average knowledge, 28 (11.2\%) had low knowledge, and few 17 (7.23\%) nurses had high knowledge regarding CAUTI.

The data in - Table 1 shows the overall mean and standard deviation (SD) of nurses' knowledge score is $12.49 \pm 2.37$.

It was found that nurses' overall knowledge on prevention of CAUTI was average, with mean percentage knowledge score of $73.47 \%$. Nurses had high knowledge with mean percentage knowledge score of $83.66 \%$ with regard to domain 2, whereas the knowledge was average with mean percentage knowledge score of 75 and $69.7 \%$ with regard to domains 1 and 3, respectively.

The data presented in - Table 2 reveal that the $p$-value computed between knowledge and age (0.013), educational qualification (0.018), and encounter with patients with CAUTI $(0.00)$ is $<0.05$, at 0.05 level of significance. Hence, the null hypothesis was rejected. There is no association between knowledge score and years of experience $(0.317)$ and source of information (0.647).

\section{Discussion}

CAUTI being one of the most common health care-associated infection. One of the reasons is that the urinary catheters once inserted among hospitalized patients remain in place even after the indication for its use ends. Limiting catheter use is the important preventive measure in decreasing the incidence of CAUTI.

Assessing the knowledge of health care professionals, especially nurses regarding catheterization and UTI, would help to manage problem related to inappropriate catheterization and CAUTI. ${ }^{1}$

Table 1 Domain wise mean, standard deviation and mean percentage of knowledge score $(n=235)$

\begin{tabular}{|l|l|l|l|l|}
\hline Domain & Items & Maximum score & Range & Mean \pm SD \\
\hline $\begin{array}{l}\text { Meaning, anatomy and physiology of } \\
\text { urinary tract and infection (domain 1) }\end{array}$ & 4 & 4 & 4 & $3.00 \pm 0.86$ \\
\hline $\begin{array}{l}\text { Etiology, risk factors, signs, and symp- } \\
\text { toms (domain 2) }\end{array}$ & 3 & 3 & 3 & $2.51 \pm 0.71$ \\
\hline $\begin{array}{l}\text { Diagnosis, treatment, prevention, and } \\
\text { complication (domain 3) }\end{array}$ & 10 & 10 & 9 & $6.97 \pm 1.67$ \\
\hline Total & 17 & 17 & 8 & $12.49 \pm 2.37$ \\
\hline
\end{tabular}

Abbreviation: SD, standard deviation.

Notes: The data show the overall mean and SD of nurses' knowledge score is $12.49 \pm 2.37$.

It was found that, nurses over all knowledge on prevention of catheter-associated urinary tract infection was average, with mean.

Table 2 Association between knowledge score and selected demographic variables $(n=235)$

\begin{tabular}{|c|c|c|c|c|}
\hline S. no. & Variables & $<$ Median $(<13)$ & $\geq$ Median $(\geq 13)$ & $p$-Value \\
\hline 1 & $\begin{array}{l}\text { Age }(y) \\
\begin{array}{l}20-25 \\
26-30 \\
31-35 \\
35-40\end{array}\end{array}$ & $\begin{array}{l}54 \\
43 \\
2 \\
2\end{array}$ & $\begin{array}{l}92 \\
36 \\
6 \\
0\end{array}$ & $0.013^{\mathrm{a}}$ (Fisher's exact test) \\
\hline 2 & $\begin{array}{l}\text { Educational qualification (y) } \\
\text { GNM } \\
\text { PBBSC } \\
\text { BSC } \\
\text { MSC }\end{array}$ & $\begin{array}{l}26 \\
19 \\
56 \\
0\end{array}$ & $\begin{array}{l}18 \\
18 \\
97 \\
1\end{array}$ & 0.018 (Fisher's exact test) \\
\hline 3 & $\begin{array}{l}\text { Years of experience }(\mathrm{y}) \\
\quad<1 \\
1-10 \\
11-20\end{array}$ & $\begin{array}{l}36 \\
63 \\
2\end{array}$ & $\begin{array}{l}50 \\
84 \\
0\end{array}$ & 0.317 (Fisher's exact test) \\
\hline 4 & $\begin{array}{l}\text { Source of information } \\
\text { Health personnel } \\
\text { Friends and relatives } \\
\text { Mass media } \\
\text { CNE } \\
\text { Others }\end{array}$ & $\begin{array}{l}39 \\
2 \\
5 \\
54 \\
1\end{array}$ & $\begin{array}{l}56 \\
0 \\
7 \\
69 \\
2\end{array}$ & 0.647 (Fisher’s exact test) \\
\hline 5 & $\begin{array}{l}\text { Encounter with patients with } \\
\text { CAUTI } \\
\text { Yes } \\
\text { No }\end{array}$ & $\begin{array}{l}94 \\
7\end{array}$ & $\begin{array}{l}98 \\
36\end{array}$ & $0.00^{\mathrm{a}}$ \\
\hline
\end{tabular}

Abbreviations: CAUTI, catheter-associated urinary tract infection; CNE, continuing nursing education.

Note: $p<0.05$

asignificant. 
In this study, the mean age of the staff nurses was $25.30 \pm 6.11$ years, and majority have completed BSc nursing (65.1\%) with the mean working experience of $6.49 \pm 2.37$ years. More than half (52.3\%) have received information through continuing nursing education and majority of the staff nurses (81.7\%) have encountered the patients with CAUTI.

In a similar study, the findings shows that majority of the staff nurses were older than 30 years of age, with associate degree and had duration of professional experience of 11 to 15 years, with higher knowledge level. ${ }^{5}$

In this study, majority of the nurses 190 (80.85\%) had average knowledge on prevention of CAUTI, whereas 28 (11.2\%) had low knowledge and 17 (7.23\%) had high knowledge regarding CAUTI. In a similar study, the findings reveal that majority of the staff nurses, 14 (46.7\%), had adequate knowledge, 10 (33.3\%) had moderately adequate knowledge, and 6 (20\%) had inadequate knowledge regarding catheter care. ${ }^{5}$

Findings of the present study showed association of level of knowledge with age (0.013), educational qualification (0.018), and encounter with patients with CAUTI $(0.00)$ is $<0.05$, at 0.05 level of significance. Similar study also showed association between the level of knowledge of staff nurses regarding catheter care with their selected sociodemographic variables like educational qualification, source of information, and attended Continuing Nursing Education program. ${ }^{5}$

Literatures show that most of the hospitals in India have not taken prevention of CAUTI as the priority. Preventing CAUTI, a common health care-associated infection (HAI), is important for improving the care of hospitalized patients and in meeting the goals for HAI reduction. Up to $60 \%$ of CAUTI are considered preventable, provided that recommended evidence-based infection-prevention practices are implemented. Guidelines for the prevention of CAUTI recommend appropriate catheter use, aseptic insertion, use of closed drainage systems, proper maintenance, and timely removal of indwelling urinary catheters, as well as the use of established practices such as hand hygiene. Prevention strategies must focus on clear indications for the insertion of urinary catheter, proper maintenance while in use, and early catheter removal. According to the NABH and JCI protocols, CAUTI insertion checklist for all patients is a must, this checklist will provide an objective feedback on the procedure and shows that the care at catheter insertion was optimal. ${ }^{6}$

Education regarding the basic catheter care, proper protocol to monitor the number, and duration of catheterization would definitely reduce the incidence of CAUTI.

Surveillance of the incidence of CAUTI on regular basis would initiative preventive measures. Education is the major health promotive tool that would increase the quality-based care in the health care settings. This study was delimited to the nurses of selected tertiary-care NABH-accredited hospital. This study could be done on a larger sample with better methodology.

\section{Conclusion}

CAUTI is one of the major health indicators in NABHaccredited hospitals. All health personnel's, especially nurses and doctors, must be trained at regular intervals regarding the prevention of CAUTI. This present study provided an insight on the knowledge of Nurses on prevention of CAUTI and indicated that nurses had average knowledge. This study has become a guide for developing education and training programs on the issues related to CAUTI in the present settings.

\section{Funding \\ None. \\ Conflict of Interest \\ None declared.}

\section{Acknowledgments}

The authors would like to acknowledge the support of The Principal, Father Muller College of Nursing, teaching faculty, experts for their guidance, and participants of the study are thanked for their whole-hearted participation.

\section{References}

1 Jain M, Dogra V, Mishra B, Thakur A, Loomba PS. Knowledge and attitude of doctors and nurses regarding indication for catheterization and prevention of catheter-associated urinary tract infection in a tertiary care hospital. Indian J Crit Care Med 2015;19(2):76-81

2 Algarni SS, Sofar DSSS, Wazqar DD. Nurses' knowledge and practices toward prevention of catheter-associated urinary tract infection at King Abdulaziz university hospital. Journal of Health. Medicine and Nursing. 2019;4(1):50-73

3 APIC. Catheter-associated urinary tract infection (CAUTI). Available at: https://apic.org/resources/topic-specific-infection-prevention/catheter-associated-urinary-tract-infection/. Accessed July 4, 2020

4 Centers for Disease Control and Prevention. CatheterAssociated Urinary Tract Infections (CAUTI). Available at: https://www.cdc.gov/infectioncontrol/guidelines/cauti/index. html. Accessed June 2, 2020

5 Prasanna K, Radhika M. Knowledge regarding catheter care among staff nurses. Int J Appl Res 2015;1(8):182-186

6 Gould C; Centers for Disease Control and Prevention. Catheterassociated Urinary Tract Infection (CAUTI) Toolkit. Available at: https://www.cdc.gov/hai/pdfs/toolkits/cautitoolkit_3_10. pdf. Accessed August 16, 2020 